\title{
ПОДХОДЫ К АНАЛИЗУ ИНСТРУМЕНТОВ ОЦЕНКИ ДЕЯТЕЛЬНОСТИ ПРОФЕССОРСКО-ПРЕПОДАВАТЕЛЬСКОГО СОСТАВА В АСПЕКТЕ РЕАЛИЗАЦИИ КАДРОВОЙ ПОЛИТИКИ ПОДРАЗДЕЛЕНИЙ ВЫСШИХ УЧЕБНЫХ ЗАВЕДЕНИЙ
}

\author{
(c) 2019 Каржанова Наталья Викторовна \\ кандидат филосовских наук, доцент кафедры иностранных языков № 3 \\ Российский экономический университет имени Г.В. Плеханова, Россия, Москва \\ Email: knatalya11@mail.ru \\ (c) 2019 Кузнецова Юлия Андреевна \\ кандидат экономических наук, доцент кафедры иностранных языков № 3 \\ Российский экономический университет им. Г.В. Плеханова, Россия, Москва \\ Email:yulia_success@mail.ru \\ (c) 2019 Прусакова Дарья Алексеевна \\ преподаватель кафедры иностранных языков № 3 \\ Российский экономический университет им. Г.В. Плеханова, Россия, Москва \\ Email: bdgid@mail.ru

\section{(c) 2019 Сидорова Елена Евгеньевна} \\ старший преподаватель кафедры иностранных языков № 3 \\ Российский экономический университет им. Г.В. Плеханова, Россия, Москва \\ Email: iksharik@gmail.com
}

В статье авторов проанализирован вопрос текущего состояния различных подходов к анализу инструментов оценки деятельности профессорско-преподавательского состава в аспекте реализации кадровой политики подразделений высших учебных заведений. Объектом исследования выступила деятельность профессорско-преподавательского состава высших учебных заведений, а предметом - анализ инструментов их оценки. Теоретическое и методологическое значения исследования заключены в систематизации подходов к анализу инструментов оценки деятельности профессорско-преподавательского состава высших учебных заведений. Практическое значение исследования заключается в определении рангов применения различных подходов к анализу инструментов оценки в аспекте реализации кадровой политики подразделений высших учебных заведений.

Ключевые слова: Подходы, анализ, инструмент, оценка, кадровая политика, деятельность, высшее учебное заведение, подразделение, аспект, профессорско-преподавательский состав.

Систематическая оценка деятельности профессорско-преподавательского состава высшего учебного заведения является приоритетным направлением в кадровой политике большинства развитых стран, ориентирующихся на инновационный путь развития системы высшего профессионального образования [7, 8].

Приведенный выше факт подтверждается результатами ряда исследований, проводимых международными консалтинговыми компаниями $(9,10,11)$ в начале 2019 года (рис. 1). Как можно увидеть, средние ранги рассматриваемого вопроса в разрезе семи проанализированных стран колеблются от двух единиц (минимальное анализируемое значение, характерное лишь для одной страны - Китай) до 4 единиц (максимальное анализируемое значение, характерное для таких стран, как США, Франция и Германия). Для прочих из анализируемых стран среднее ранговое значение оценки деятельности профессорско-преподавательского состава находилось в пределах трех единиц. Совокупный средний ранг анализируемых систем составил три единицы (с округлением до целых величин).

Обозначив процедуру оценки деятельности профессорско-преподавательского состава [3, 4, 5], как весьма приоритетную, отметим, что в ее основу положен ряд инструментов, различаю- 


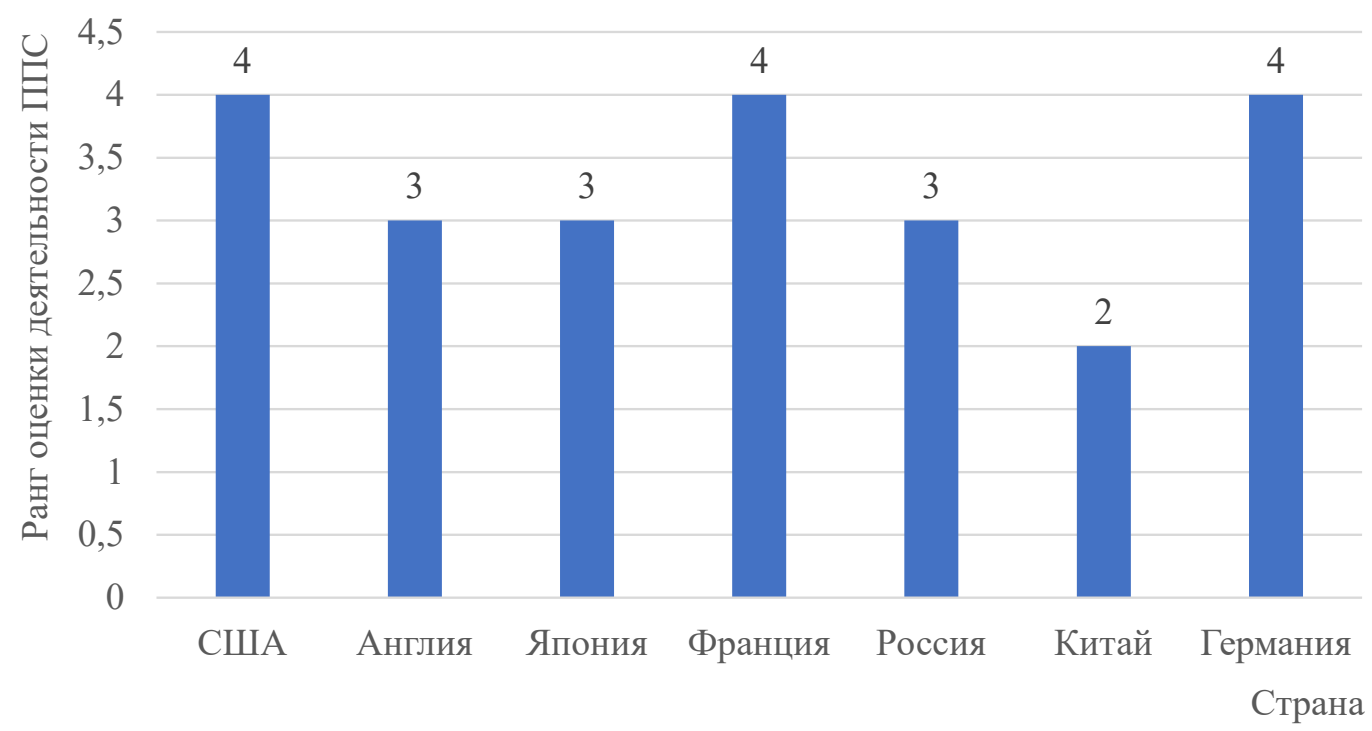

Рис. 1. Результаты исследований систем высшего профессионального образования [6, с. 89] в ряде развитых стран в 2018 году в аспекте среднего по стране ранга оценки деятельности профессорско-преподавательского состава в совокупном ранговом пространстве* $[9,10]$.

\footnotetext{
* Минимальное значение анализируемого показателя процесса оценки в совокупном ранговом пространстве составляет 1 единицу (характеризует наименьший из возможных приоритетов в кадровой политике высших учебных заведений), а максимальное 10 единиц (характеризует наибольший из возможных приоритетов в кадровой политике высших учебных заведений). Сама величина исходного ранга для высших учебных заведений той или иной страны представлена целыми числами от 1 до 10, а средняя величина дробными, с округлением (для удобства дальнейшего анализа) до целых
}

щихся в основном по типу аналитического аппарата (таблица 1).

Многообразие инструментов оценки деятельности профессорско-преподавательского состава на практике, в целях достижения максимальной эффективности как на уровне высшего учебного заведения [2, с. 91] в целом, так и его отдельных подразделений, инициирует потребность в их комплексном анализе.

Ввиду этого, для оптимизации ключевых показателей эффективности, заложенных в кадровой политике высшего учебного заведения в Российской Федерации [1, с. 77] и его подразделений, были выделены следующие подходы, отраженные в таблице 2.

Сводная характеристика положительных и отрицательных моментов каждого из обозначенных выше подходов приведена в таблице 3 .

В целях данной публикации было проведано интегральное ранжирование подходов к анализу инструментов оценки деятельности профессорско-преподавательского состава высших учебных заведений [4, с. 89] в аспекте учета особенностей функционирования их подразделений (рис. 2).
Данные рисунка 2 позволяют сделать следующие выводы:

- все шесть анализируемых подходов к анализу инструментов оценки деятельности профессорско-преподавательского состава высших учебных заведений являются в достаточной мере уникальными, что подтверждается отсутствием в значениях их рангов тождественных величин;

- среднее значение ранга по всем анализируемым подходам к анализу инструментов оценки равно 4 единицы (округленно до целой величины);

- превалирующие позиции здесь занимают дифференцированный и интегральный подходы к анализу инструментов оценки с уровнями рангов в 5 и 7 из 10 единиц соответственно;

- низовые позиции с рангами в 1 и 2 единицы из 10 возможных характеризуются соответственно директивный и хаотичный подходы к анализу инструментов оценки;

- промежуточное положение в анализируемом ряду подходов к анализу инструментов оценки занимает эмпирический подход с 3 ранговыми единицами из 10 возможных. 
Таблица 1. Виды инструментов, применяемых для оценки деятельности профессорскопреподавательского состава высших учебных заведений в Российской Федерации

\begin{tabular}{|l|l|l|}
\hline \multicolumn{1}{|c|}{ Вид инструмента оценки } & \multicolumn{1}{|c|}{$\begin{array}{l}\text { Содержание инструмента } \\
\text { (аналитический аппарат) }\end{array}$} & $\begin{array}{c}\text { Частота применения инструмента } \\
\text { на практике }\end{array}$ \\
\hline Статистический & $\begin{array}{l}\text { Аналитический аппарат инструмента } \\
\text { основан на применении статистиче- } \\
\text { ских методов оценки }\end{array}$ & $\begin{array}{l}\text { Инструмент достаточно часто приме- } \\
\text { няется во многих высших заведениях } \\
\text { Российской Федерации }\end{array}$ \\
\hline Экономико-математический & $\begin{array}{l}\text { Аналитический аппарат инструмента } \\
\text { основан на применении экономико- } \\
\text { математических методов оценки }\end{array}$ & $\begin{array}{l}\text { Инструмент достаточно часто приме- } \\
\text { няетс во многих высших заведениях } \\
\text { Российской Федерации }\end{array}$ \\
\hline Матричный (графический) & $\begin{array}{l}\text { Аналитический аппарат инструмента } \\
\text { основан на применении матрич- } \\
\text { но-графических методов оценки }\end{array}$ & $\begin{array}{l}\text { На практике в Российской Федера- } \\
\text { ции данный инструмент применяет- } \\
\text { ся достаточно редко }\end{array}$ \\
\hline Логический & $\begin{array}{l}\text { Аналитический аппарат инструмента } \\
\text { основан на применении логических } \\
\text { методов оценки }\end{array}$ & $\begin{array}{l}\text { На практике в Российской Федера- } \\
\text { ции данный инструмент применяет- } \\
\text { ся редко }\end{array}$ \\
\hline Эвристический и прочие & $\begin{array}{l}\text { Аналитический аппарат инструментата } \\
\text { основан на применении эвристиче- } \\
\text { ских методов оценки }\end{array}$ & $\begin{array}{l}\text { На практике в Российской Федера- } \\
\text { ции данный инструмент практиче- } \\
\text { ски не применяется }\end{array}$ \\
\hline
\end{tabular}

Таблица 2. Подходы к анализу инструментов оценки деятельности профессорско-преподавательского состава высших учебных заведений

\begin{tabular}{|l|l|l|}
\hline \multicolumn{1}{|c|}{ Наименование подхода } & \multicolumn{1}{|c|}{ Содержание подхода } & $\begin{array}{l}\text { Частота применения } \\
\text { подхода на практике }\end{array}$ \\
\hline Директивный & $\begin{array}{l}\text { Подход предполагает проведение анализа выбранных } \\
\text { инструментов оценки на основе действующих норм }\end{array}$ & Часто \\
\hline Эмпирический & $\begin{array}{l}\text { Подход предполагает проведение анализа выбранных } \\
\text { инструментов на основе текущего опыта аналитика }\end{array}$ & Достаточно часто \\
\hline Дифференцированный & $\begin{array}{l}\text { Подход предполагает проведение анализа каждого из } \\
\text { выбранных инструментов в отдельности }\end{array}$ & Достаточно часто \\
\hline Интегральный & $\begin{array}{l}\text { Подход предполагает проведение анализа всех исполь- } \\
\text { зуемых инструментов совместно }\end{array}$ & Редко \\
\hline Хаотичный & $\begin{array}{l}\text { Анализ инструментов оценки осуществляется на основе } \\
\text { вероятностных сценариев работы системы }\end{array}$ & Достаточно редко \\
\hline
\end{tabular}

Таблица 3. Сводная характеристика положительных и отрицательных моментов каждого из подходов к анализу инструментов оценки деятельности профессорско-преподавательского состава высших учебных заведений

\begin{tabular}{|l|l|l|}
\hline Наименование подхода & \multicolumn{1}{|c|}{$\begin{array}{c}\text { Основные положительные моменты, } \\
\text { присущие подходу }\end{array}$} & $\begin{array}{l}\text { Основные отрицательные моменты, } \\
\text { присущие подходу }\end{array}$ \\
\hline Директивный & $\begin{array}{l}\text { Минимальные затраты времени на при- } \\
\text { нятие управленческого решения }\end{array}$ & $\begin{array}{l}\text { Практическое отсутствие учета факто- } \\
\text { ров, воздействующих на объект анализа } \\
\text { в прошлом и настоящем }\end{array}$ \\
\hline Эмпирический & $\begin{array}{l}\text { Учет влияния факторов, воздействую- } \\
\text { щих на объект анализа в прошлом }\end{array}$ & $\begin{array}{l}\text { Недостаточный учет факторов, воздей- } \\
\text { ствущих на объект анализа в настоя- } \\
\text { щем }\end{array}$ \\
\hline Дифференцированный & $\begin{array}{l}\text { Высокий уровень детализации резуль- } \\
\text { татов анализа по каждому из применя- } \\
\text { емых инструментов }\end{array}$ & $\begin{array}{l}\text { Значительные сложности в объеди- } \\
\text { неном представлении результатов } \\
\text { анализа }\end{array}$ \\
\hline Интегральный & $\begin{array}{l}\text { Результаты анализа по всем их приме- } \\
\text { ненных инструментов представлены } \\
\text { единым композиционным массивом }\end{array}$ & $\begin{array}{l}\text { Относительно низкий уровень детали- } \\
\text { зации результатов анализа по каждому } \\
\text { из применяемых инструментов }\end{array}$ \\
\hline Хаотичный & $\begin{array}{l}\text { учет влияния факторов, воздейству- } \\
\text { ющих на объект анализа в прошлом и } \\
\text { настоящем }\end{array}$ & $\begin{array}{l}\text { В значительной степени вероятностный } \\
\text { характер результатов, полученных в } \\
\text { ходе проведения анализа инструментов } \\
\text { оценки }\end{array}$ \\
\hline
\end{tabular}




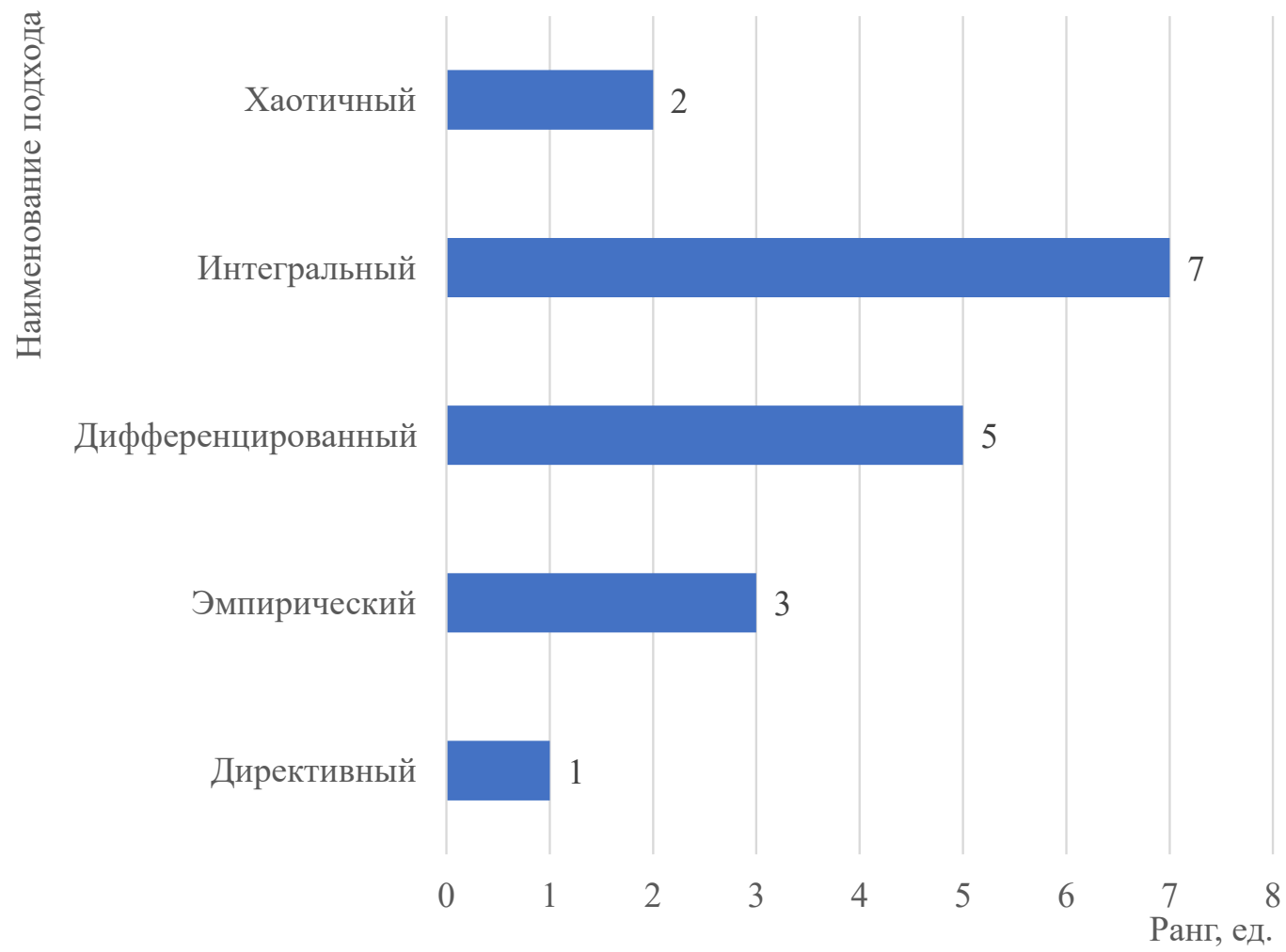

Рис. 2. Результаты интегрального ранжирования подходов* к анализу инструментов оценки деятельности профессорско-преподавательского состава высших учебных заведений в аспекте учета особенностей функционирования их подразделений

* Примечания:

- процесс интегрального ранжирования анализируемых подходов был проведен на основе нейросетевого моделирования в программной среде STATISTICA Automated Neural Networks;

- методической основой для ранжирования подходов послужили собственные наработки авторов по анализируемой проблеме;

- исполнителями поставленной задачи выступили авторы данной публикации, совместно с группой экспертов, квалифицированных в обозначенных выше областях исследования;

- минимальное значение ранга для анализируемых подходов составило 0 единиц (практическая значимость подхода отсутствует);

- максимальное значение ранга для анализируемых подходов составило 10 единиц (практическая значимость подхода является максимальной).

Таким образом, можно сделать вывод, что оценка деятельности профессорско-преподавательского состава высшего учебного заведения может быть проведена с использованием следующих инструментов: статистические, экономико-математические, матричные (графические), логистические, эвристические и т.д.

Для анализа указанных инструментов оценки на практике в Российской Федерации возможны к применению директивный, эмпири- ческий, дифференцированный, интегральный и хаотичный подходы.

Сводная характеристика положительных и отрицательных моментов каждого из подходов к анализу инструментов оценки деятельности профессорско-преподавательского состава высших учебных заведений в аспекте реализации их кадровой политики позволила выделить в качестве превалирующих - дифференцированный и интегральный подходы. 


\section{Библиографический список}

1. Аввакумова И. В., Прусакова Д. А. и др. Экономические аспекты корпоративной интеграции подразделений высшего учебного заведения в целях повышения качества образовательного процесса / И.В. Аввакумова, Д.А. Прусакова, Е.Е. Сидорова, М.С. Циликова // Экономические науки - Москва: Изд-во ООО «24-Принт», 2018. - № 10.- С. 75-79.

2. Коваленко М.В. Особенности формирования и реализации кадровой политики высших учебных заведений / М.В. Коваленко // Фундаментальные и прикладные научные исследования: актуальные вопросы, достижения и инновации - Пенза: Изд-во «Наука и Просвещение», 2018.- С. 91-95.

3. Николаева E. A., Григорьева И.В. и др. К аспектам влияния оценки эффективности деятельности профессорско-преподавательского состава высшего учебного заведения на укрепление экономической безопасности Российской Федерации / Е.А. Николаева, И.В. Григорьева, И.С. Казимирова, Е.И. Соколова // Экономические науки - Москва: Изд-во ООО «24-Принт», 2019. - № 3.- С. $62-67$.

4. Николаева Е. А., Кузнецова Ю.А. и др. Инструменты реализации стратегических инициатив высшего учебного заведения в целях повышения качества образовательного процесса / Е.А. Николаева, Ю.А. Кузнецова, Е.Л. Агибалова, Н.В. Каржанова // Экономические науки - Москва: Изд-во ООО «24-Принт», 2018. - № 9.C. 87-90.

5. Попова С. А., Трихина И.А. Формирование подходов к оценке эффективности деятельности профессорскопреподавательского состава в кадровой политике высшего учебного заведения / С.А. Попова, И.А. Трихина // Вестник Евразийской науки - Москва: Изд-во ООО «Издательство «Мир науки», 2019._ № 1.- С. 1-8.

6. Соколова Е. И. К вопросу обеспеченности сферы высшего профессионального образования в российской федерации стратегиями развития экономической безопасности / Е.И. Соколова // Экономические науки Москва: Изд-во ООО «24-Принт», 2019.- № 6.-С. 87-91.

7. Brewer, P. D. and Brewer, K. L. 2010. Knowledge management, human resourcemanagement, and higher education: a theoretical model. Journal of Education for Business, 85(6), pp. 330-335.

8. Elliott, K. 2015. Teacher Performance Appraisal: More about Performance or Development?. Australian Journal of teacher education, 40(9), pp. 101-116.

9. Компания «Ernst\&Young» [Электронный ресурс]: аналитические материалы - Официальный сайт компании «Ernst\&Young», 2019.- Режим доступа: https://www.ey.com/ru/

10. Компания «KPMG» [Электронный ресурс]: аналитические материалы - Официальный сайт компании «KPMG», 2019.- Режим доступа: https://home.kpmg/ru/ru/

11. Компания «PricewaterhouseCoopers» [Электронный ресурс]: аналитические материалы - Официальный сайт компании «PricewaterhouseCoopers», 2019.- Режим доступа: https://www.pwc.ru 